\title{
Differentially Expressed Proteins in Response to Resuscitation of Non- Culturable Cells of Mycobacterium tuberculosis H37Rv: Potential New Drug Targets
}

\author{
Ravi Kr. Gupta1, Bhavnesh Kumar', Deepa Bisht ${ }^{2}, K^{2}$ iran Katoch ${ }^{2}$, Kalyan Mitra ${ }^{3}$ and \\ Ranjana Srivastava ${ }^{1 *}$
}

\author{
${ }^{1}$ Microbiology Division, Central Drug Research Institute, CSIR, India \\ ${ }^{2}$ Department of Biochemistry, National JALMA Institute for Leprosy \& Other Mycobacterial Diseases (ICMR), India
}

${ }^{3}$ Electron Microscopy Unit, Central Drug Research Institute, CSIR, India *Corresponding author: Dr. Ranjana Srivastava., Microbiology Division, Central Drug Research Institute,
CSIR, Jankipuram Sector 10. Sitapur Road, Lucknow - 226031, India, Tel: +91-522-4007058, E-mail:
ranjanasrivastava5@gmail.com

\begin{abstract}
The major obstacle in TB eradication is attributed to the dormant state of the TB bacilli, Mycobacterium tuberculosis and is characterized by asymptomatic, non-culturability and antibiotic resistant state of disease. Conventional antibiotic therapy is only applicable to the active form of the disease. These non-replicating cells can resume the growth in immunosuppression state and cause the symptomatic disease. The non-culturability (NC) can be generated in vitro in $M$. tuberculosis and their resuscitation to active growth has been demonstrated by the five resuscitation promoting factors (Rpfs) encoded by M. tuberculosis supporting the applicability of Rpf mediated resuscitation as a model for the study of dormancy and reactivation. In this study, M. tuberculosis H37Rv cells in replicating, non-culturable and resuscitation phase were generated in vitro and analysed by scanning electron microscopy for morphological changes that occurred during the transition of replicating bacilli to non-culturable to resuscitation phase. Two dimensional gel electrophoresis (2-DE) and MALDI-TOF mass spectrometry was performed for proteins differentially expressed in three different stages. The analysis led to the identification of fourteen mycobacterial proteins that were differentially expressed during non-culturable and resuscitation phase compared to replicating. Five of the unique proteins identified in the resuscitation and NC phase by $2 \mathrm{DE}$ were also confirmed by western immunoblotting. The differential expression of 14 proteins in NC and resuscitation phase was also regulated at transcriptional level as revealed by real time RT-PCR analysis and could thus become potential drug targets
\end{abstract}

\section{Keywords}

M. tuberculosis, Non-culturable cells, 2-DE, Scanning electron microscopy, Resuscitation promoting factors

\section{Introduction}

Upon infection with Mycobacterium tuberculosis, only an estimated $10 \%$ of the people develop the active disease and in the rest population bacillus may lie dormant in the body for decades in a latent stage. The epidemiological data suggest that possibly up to one-third of the world's population is latently infected with this microorganism [1]. The latent stage of infection is normally associated with the bacteria surviving in the granuloma for years in a dormant state with low or no metabolic activity [2]. These bacteria appear to be resistant to standard chemotherapy and are capable of reactivating under immune suppression.

Several in vitro and in vivo animal models have been established in an attempt to mimic the latent state and subsequent reactivation of $M$. tuberculosis and contributed significantly to our understanding of the biology of MTB [3-5]. Dormancy has been duplicated in vitro by growing tubercle bacilli to the extended stationary phase for 5-6 months or subjecting them to nutrient starvation or gradually decreasing the supply of oxygen which shift the actively replicating tubercle bacilli into the state of dormancy [4,5]. While latent bacilli can be reactivated in vivo under generalized immunosuppression, in vitro generated dormant cells can resume growth upon addition of a family of protein known as resuscitation promoting factors (Rpfs) isolated from Micrococcus luteus or Mycobacterium tuberculosis [6,7]. Mycobacterial Rpfs have been demonstrated to play an important role in reactivation of chronic infection and are important for in vivo persistence of $M$. tuberculosis in mice $[8,9,10]$. The expression of $r p f$ genes have been reported in human lung tissue and sputum of pulmonary TB patients. The non-culturable latent bacilli present in the sputum of TB patients could be resuscitated by mycobacterial Rpfs [11]. This was the first documentation of Rpf dependent resuscitation of non-culturable latent $M$. $t b$ population in the sputum of TB patient [11]. The in vitro model of non culturability and subsequent resuscitation by Rpf proteins thus is not only crucial for understanding the molecular mechanisms that controls the transition of replicating mycobacteria to a dormant state and vice versa but also may be examined for its applicability in latent infection and reactivation.

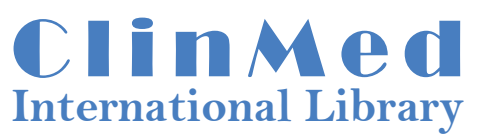

Citation: Gupta RK, Kumar B, Bisht D, Katoch K, Mitra K, et al. (2015) Differentially Expressed Proteins in Response to Resuscitation of Non-Culturable Cells of Mycobacterium Tuberculosis H37Rv: Potential New Drug Targets. Int J Respir Pulm Med 2:025

Received: April 24, 2015: Accepted: July 29, 2015: Published: August 03, 2015 Copyright: ( 2015 Gupta RK. This is an open-access article distributed under the terms of the Creative Commons Attribution License, which permits unrestricted use, distribution, and reproduction in any medium, provided the original author and source are credited. 
Various proteomics and transcriptomics studies have been performed to identify proteins and genes differentially expressed in stationary phase, hypoxia and nutrient starvation, leading to identification of different pathways and genes involved in the persistence $[4,5,12-14]$. In this investigation, we report the proteins differentially expressed in $M$. tuberculosis during non-culturable and resuscitation phase by the influence of Rpf proteins with the 2-D gel electrophoresis. The morphological changes that occurred during the transition of replicating log phase bacilli to non-culturable to resuscitation phase were studied by scanning electron microscopy. The role of the unique proteins identified in nonculturable and resuscitation phase may further be evaluated at molecular level for the prevention and control of dormancy and reactivation of tuberculosis infection.

\section{Methods and Materials}

M. tuberculosis $\mathrm{H} 37 \mathrm{Rv}$ was grown in Sauton's medium containing ADC (Becton Dickinson, USA) and tween-80 (0.05\% v/v) without shaking at $37^{\circ} \mathrm{C}$. The 2 -DE analysis was performed in PROTEAN IEF Cell and PROTEAN II XI (Bio-Rad, Hercules, CA, USA). Mass spectra was acquired using Autoflex II TOF/TOF 50 (Bruker Daltonik $\mathrm{GmbH}$, Leipzig, Germany) in positive reflectron mode, in the detection range of $500-3000 \mathrm{~m} / \mathrm{z}$. Chemicals were purchased from Bio-Rad (USA) or Sigma-Aldrich (USA). Real time-PCR was performed in Light Cycler LC480 II (Roche).

\section{Mycobacterial growth conditions and sample preparation for $2-\mathrm{DE}$}

Non-culturable (NC) state was achieved as described previously by Shleeva et al. [6,15]. Briefly, NC cells of M. tuberculosis H37Rv were obtained by prolonged incubation of culture in Sauton's medium containing tween-80 $(0.05 \% \mathrm{v} / \mathrm{v})$ and ADC for 6 months at $37^{\circ} \mathrm{C}[6,15,16]$. Samples were taken at regular intervals and passed through 23-gauge syringe before plating to make the culture homogenous. Plating was done on MB7H10 agar medium containing OADC (Becton Dickinson, USA). After 6 months of incubation, $M$. tuberculosis became non-culturable as $\mathrm{CFU}$ was negligible (less than 5 cells $\mathrm{ml}^{-1}$ ).

Resuscitation of NC cells was induced as described previously by cell free culture supernatant of log phase $\left(\mathrm{OD}_{600} 0.5\right)$ M. tuberculosis $\mathrm{H} 37 \mathrm{Rv}$ culture $[6,10,13,15]$. The cells were removed by centrifugation at $6000 \mathrm{~g}$ for $10 \mathrm{~min}$ and supernatant was filter sterilized with $0.22 \mu \mathrm{m}$ filter (Whatman) at $4^{\circ} \mathrm{C}$ and used within $20 \mathrm{~min}$. Three samples were prepared for each culture condition i.e. $\log$ phase $\left(\mathrm{OD}_{600} 0.6,3\right.$ weeks old culture), non-culturable ( $\mathrm{OD}_{600} 4.5,6$ month old culture) and resuscitation phase $\left(\mathrm{OD}_{600} 0.24,7\right.$ days after resuscitation) and per sample three 2-DE gels were produced. Mycobacterial cell lysate was prepared according to the method of Brodie et al. [17]. Cells were washed with normal saline and suspended in sonication buffer [50mM Tris- $\mathrm{HCl}$ containing $10 \mathrm{mM} \mathrm{MgCl}_{2}, 0.1 \%$ sodium azide, $1 \mathrm{mM}$ phenyl methyl sulfonyl fluoride (PMSF) and $1 \mathrm{mM}$ ethylene glycol tetra acetic acid (EGTA); $\mathrm{pH} 7.4$ ] at a concentration of $1 \mathrm{~g}$ wet cell mass per $5 \mathrm{ml}$ and then broken by sonication for $30 \mathrm{sec}$ on and $60 \mathrm{sec}$ off position for total $15 \mathrm{~min}$ at $4^{\circ} \mathrm{C}$. The homogenate was centrifuged at $12,000 \mathrm{~g}$ for $20 \mathrm{~min}$ at $4^{\circ} \mathrm{C}$. Pellets were discarded and supernatant was stored at $-20^{\circ} \mathrm{C}$ until used. Cell lysate proteins were precipitated using published protocol [18]. Cell lysates were treated with $1 \%$ sodium dodecyl sulphate (SDS) and then subjected to TCAacetone precipitation procedure. TCA $(10 \% \mathrm{v} / \mathrm{v})$ was added to the cell lysate, mixture was incubated at $-20^{\circ} \mathrm{C}$ overnight and precipitated protein was collected by centrifugation at $18000 \mathrm{~g}, 15 \mathrm{~min}, 4^{\circ} \mathrm{C}$. It was again washed with $100 \%$ ice cold acetone and allowed to air dry. The protein pellet was suspended in appropriate volume of 2-DE rehydration buffer [ $8 \mathrm{M}$ urea, $2 \%$ CHAPS $(\mathrm{w} / \mathrm{v}), 50 \mathrm{mM}$ dithiothreitol (DTT), 0.2\% Bio-Lyte 3/10 ampholyte, $0.001 \%$ bromophenol blue] (Bio-Rad, USA) and the protein concentration was estimated by Bradford method using bovine serum albumin as standard.

\section{2-DE and mass spectrometric analysis}

Isoelectric focusing (IEF) was carried out using the method of "in-gel-rehydration" with slight modifications [19]. An immobilized $\mathrm{pH}$ gradient (IPG) strip of $\mathrm{pH} 4-7$ and length $17 \mathrm{~cm}$ (Bio-Rad, USA) was rehydrated overnight at $20^{\circ} \mathrm{C}$ with $500 \mu \mathrm{g}$ protein, which was mixed with 2-DE rehydration buffer. Strips were then focused on an IEF unit PROTEAN IEF Cell (Bio-Rad, USA) at $20^{\circ} \mathrm{C}$ using the following four-step program: (i) $0-250 \mathrm{~V}$ for $2 \mathrm{~h}$ in linear mode; (ii) $250 \mathrm{~V}$ constant for $2 \mathrm{~h}$ in rapid mode; (iii) $250-5000 \mathrm{~V}$ for $4 \mathrm{~h}$ in linear mode; and (iv) $5000 \mathrm{~V}$ constant until $35 \mathrm{kVh}$ reached. The current limit was set at $50 \mu \mathrm{A}$ per strip. After IEF, strip was equilibrated for $15 \mathrm{~min}$ in equilibration buffer I [6M urea, $2 \%$ SDS (w/v), $0.375 \mathrm{M}$ Tris; $\mathrm{pH} 8.8,20 \%$ glycerol (v/v)] containing $130 \mathrm{mM}$ DTT followed by equilibration buffer II containing $135 \mathrm{mM}$ iodoacetamide instead of DTT for $15 \mathrm{~min}$. Proteins were separated in second dimension on $12 \%$ SDS-polyacrylamide gels [17] in a vertical electrophoretic unit PROTEAN II XI (Bio-Rad, USA) at a constant voltage of 250V for 5-6 $\mathrm{h}$ at $100 \mathrm{~W}$ and gels were stained with Coomassie brilliant blue R250 to visualize proteins. Images of gels were acquired by Chemidoc [Bio-Rad, Segrate (Milan), Italy] using Quantity One software (BioRad, USA) and differentially expressed proteins were analysed using PDQuest software (Bio-Rad, USA).

Student t-test was used for the statistical analysis by PDQuest software. The system picks up the spots with differential intensity of significant levels built in the system. Equal amount of protein $(500 \mu \mathrm{g})$ was loaded on all gels and experiment was repeated three times for each condition. For In-gel digestion of protein spots with trypsin protocol of Shevchenko and co-workers [18] was followed. Protein spots of interest were excised from the coomassie blue stained 2D gels using spot picker Investigator ProPic (Genomic Solutions Ltd., UK) and collected in 96 well PCR plate. Digestion of proteins and spotting of peptides on matrix assisted LASER desorption/ionization-time of flight (MALDI-TOF) target plate was carried out using protein digester Investigator ProPrep (Genomic Solutions, Huntingdon, UK). The gel plugs were destained and dehydrated by washing three times (for $10 \mathrm{~min}$ ) with $25 \mathrm{mM} \mathrm{NH}_{4} \mathrm{HCO}_{3}$ and 50\% acetonitrile (ACN) (1:1 $\mathrm{v} / \mathrm{v})$. Dried gel plugs were treated with freshly prepared $10 \mathrm{mM}$ DTT in $50 \mathrm{mM} \mathrm{NH}_{4} \mathrm{HCO}_{3}$ at $56^{\circ} \mathrm{C}$ for $45 \mathrm{~min}$. After incubation, the DTT was replaced quickly by the same volume of freshly prepared $55 \mathrm{mM}$ iodoacetamide in $50 \mathrm{mM} \mathrm{NH}_{4} \mathrm{HCO}_{3}$ for $30 \mathrm{~min}$ and then dehydrated with $100 \% \mathrm{ACN}$. The dried gel pieces were incubated for $12 \mathrm{~h}$ at $37^{\circ} \mathrm{C}$ with $25 \mathrm{mM} \mathrm{NH} \mathrm{HCO}_{3}$ containing $0.02 \mu \mathrm{g} / \mu \mathrm{l}$ of mass spectrometry grade trypsin (Promega, USA). The resulting peptides were extracted twice from the gel pieces, using peptide extraction buffer $[1: 1 \mathrm{v} / \mathrm{v}$ mixture of $70 \%$ ACN and $1 \%$ formic acid (FA) and transferred to a new 96 well PCR plate.

Prior to mass spectrometric analysis, samples were desalted and concentrated on C-18 ZipTips (Millipore, USA) using the manufacturer's protocol. ZipTips were eluted on MTP 384 target plate with $2 \mu$ l of $\alpha$-cyano-4-hydroxycinnamic acid (HCCA) saturated solution dissolved in $50 \% \mathrm{ACN}(\mathrm{v} / \mathrm{v}), 0.2 \% \mathrm{FA}$. Mass spectra of digested protein were acquired using Autoflex II TOF/TOF 50 (Bruker Daltonik Gmbh,Germany) in positive reflectron mode, in the detection range of $500-3000 \mathrm{~m} / \mathrm{z}$.

The proteolytic masses obtained were then evaluated using MASCOT search, a peptide mass fingerprinting tool. Peak detection in MALDI spectra and submission of peak lists to the database were performed using the MASCOT wizard (Matrix Science, UK). Peptide mass tolerance was set to 50ppm with carbamidomethyl-cystein set as fixed modification, oxidation of methionine as variable modification and one missed cleavage site allowed.

\section{Western blotting}

Monoclonal antibodies of Rv3418c and Rv2031c were obtained from Colorado State University, USA (http://www.cvmbs.colostate. edu/microbiology/tb/monocsu.html). Polyclonal antibodies for Rv2623, Rv1308 and Rv1479 were raised by immunization 
of recombinant protein in rabbit. Rabbits were immunized subcutaneously with $200 \mu \mathrm{g}$ of recombinant protein, emulsified in polyacrylamide gel as an adjuvant and boosted 21 days later with half the amount of antigen. It was maintained in the CDRI animal house facility and the experimental protocol was approved by the institutional animal ethics committee. Serum was collected from the blood of the immunized rabbit and stored at $-20^{\circ} \mathrm{C}$. One-dimensional immunoblotting was performed by running 12 to $15 \%$ SDS polyacrylamide gels. $50 \mu \mathrm{g}$ protein samples from replicating, extended stationary phase and resuscitation phase was run on SDS-PAGE and transferred onto a nitrocellulose membrane, Hybond-C (Amersham life sciences, USA). Immunoblotting was performed by standard protocol $[19,20]$. The blot was probed with the polyclonal antibodies (1:500 dilutions) and monoclonal antibodies with (1:100 dilutions) and developed with horseradish peroxidase-conjugated secondary antibody with diaminobenzidine as a substrate.

\section{RNA isolation and cDNA synthesis}

RNA was isolated from each culture condition described above, i.e., $\log$ phase, non-culturable and resuscitation phase in triplicate from the same culture samples used for 2-DE experiments of $M$. tuberculosis H37Rv. RNA isolation and cDNA synthesis were performed as described previously [15]. Briefly, from various growth phases described above $30 \mathrm{ml}$ culture was harvested in triplicate from three independent experiment setup. RNA isolation was done according to kit protocol (RNeasy mini kit, Qiagen) and quantified by Qubit fluorometer (Invitrogen). Each RNA sample was treated with DNaseI, RNase-free (Fermentas) and heat inactivated according to manufacturer's instructions. RNA integrity was checked by bioanalyzer (Agilent Technologies, U.S.A.). DNA contamination was checked by (no-RT) PCR for each RNA sample in a gradient cycler (Master-cycler gradient, Eppendorf, Germany) using 16S rRNA primer. No amplification was seen after 30 cycles of amplification. 300-400ng RNA was used for cDNA synthesis using random hexamer primers by RevertAid ${ }^{\mathrm{Tm}}$ first strand $\mathrm{H}$-minus cDNA synthesis kit (Fermentas).

\section{Real time-PCR}

Real-time quantitative PCR was performed in LightCycler 480II instrument (Roche) using Light Cycler 480 SYBR Green I Master kit (Roche) as described previously. Internal primers for each gene were designed using DNAstar primer design software and purchased from Sigma-Aldrich. All primer sets were optimized for annealing temperature and concentration to ensure that only a single product of the correct size should be amplified. For LightCycler reaction, a master mix of the following components was prepared: 7.0 $\mu \mathrm{l} \mathrm{PCR} \mathrm{grade}$ water, $1.0 \mu \mathrm{l}(0.5 \mu \mathrm{M})$ forward primer, $1.0 \mu \mathrm{l}(0.5 \mu \mathrm{M})$ reverse primer, $10 \mu \mathrm{l} 2 \mathrm{X}$ master mix, $1.0 \mu \mathrm{l}$ cDNA (50-100 ng). Sealed the multiwell plate with sealing foil, centrifuged at $1500 \mathrm{~g}$ for $1 \mathrm{~min}$ and loaded in the Light Cycler 480II instrument. Amplification was performed in triplicate wells for each sample analyzed; control reaction consisting of no template (water) was run with all the reactions. In each set of reaction, 16S rRNA was used as a reference gene for normalization of cDNA amount. Relative quantification analysis was done as described previously [15] using efficiency calibrated model [21]. Melting curve analysis was done for each reaction product to ensure the specificity of amplified product. The results were expressed as mean relative expression ratio \pm standard deviation (SD) for each gene between non-culturable and resuscitation phase using log phase RNA as a positive calibrator. Relative expression ratio was calculated from triplicate normalized ratio for each gene with SD. Student t-test was performed for significance of relative expression ratio and $\mathrm{p}<0.05$ was considered significant.

\section{Scanning electron microscopy}

Replicating, non-culturable and resuscitation phase cells of $M$. tuberculosis $\mathrm{H} 37 \mathrm{Rv}$ were aliquoted from the triplicate samples used for the 2-DE experiments. $200 \mu \mathrm{l}$ cells from each condition were fixed in $4 \%$ paraformaldehyde and $2 \%$ glutaraldehyde in $0.1 \mathrm{M}$ sodium cacodylate buffer for $4 \mathrm{~h}$ at room temperature $\left(22^{\circ} \mathrm{C}\right)$. After washing in cacodylate buffer, suspensions were placed on poly-L-lysine coated glass chips and allowed to adhere for 10 minutes at room temperature. Samples were post-fixed in $1 \%$ osmium tetroxide and subsequently dehydrated through an ascending ethanol series, critical point dried and coated with Au-Pd (80:20) using a Polaron E5000 sputter coater. Samples were examined in a Philips XL 30 ESEM at an accelerating voltage of $20 \mathrm{kV}$. Micrographs were taken at magnifications of 2000X to $10000 \mathrm{X}$. At least 20 different fields from two stubs (for each sample) were analyzed.

\section{Results and Discussion}

\section{Proteins differentially expressed in resuscitation and nonculturable phase}

The mycobacterial proteins expressed during resuscitation and

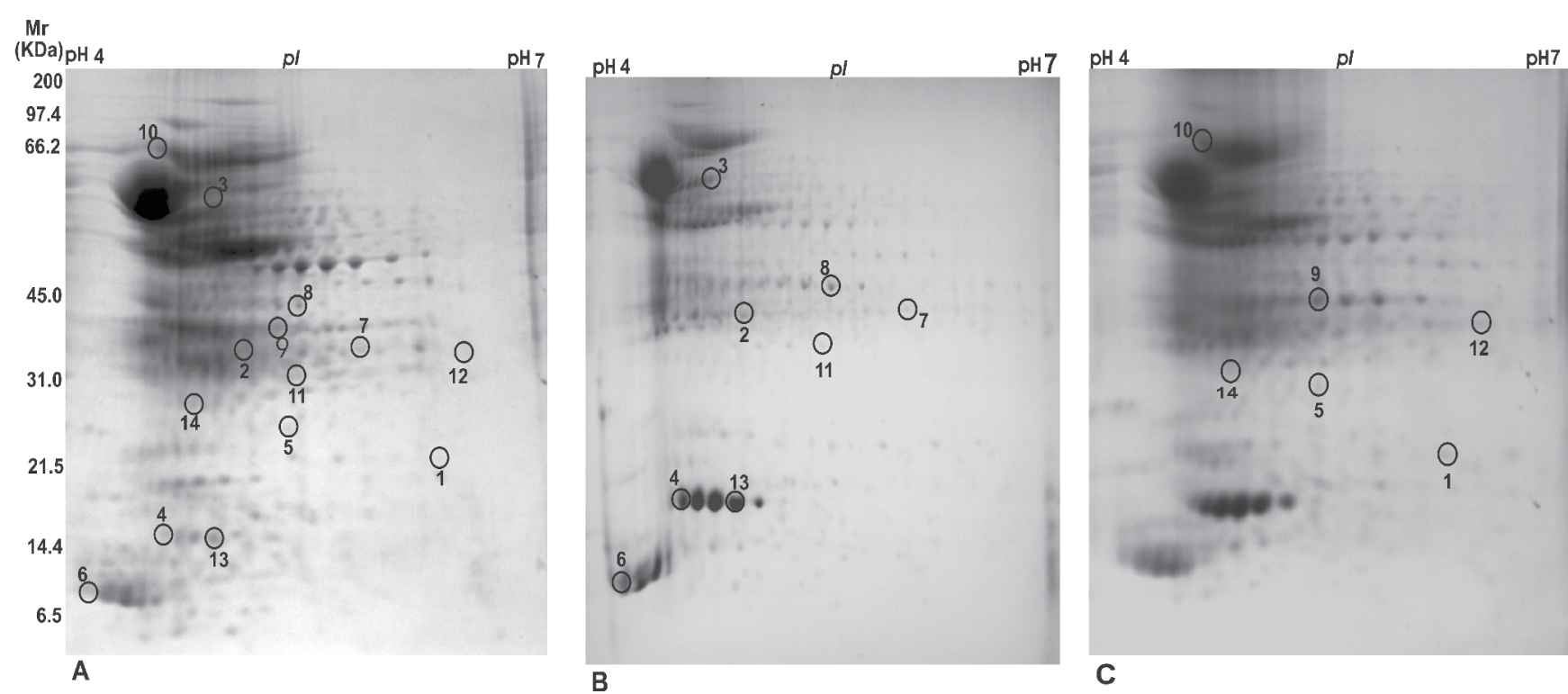

Figure 1: Coomassie blue stained 2-DE identity of protein spots generated by the PDQuest software (Bio-Rad, USA) of replicating (A), non-culturable (B) and resuscitation phase $(\mathrm{C})$ culture of $M$. tuberculosis $\mathrm{H} 37 \mathrm{Rv}$. An immobilized $\mathrm{pH}$ gradient strip of $\mathrm{pH}$ range 4 to 7 and $17 \mathrm{~cm}$ length was used for 2-DE analysis. PDQuest Software identified 107 protein spots in non-culturable and 112 protein spots in resuscitation phase compared to replicating phase culture. However, only 14 spots were identified by MALDI-TOF spectrometry which were unique to non-culturable or resuscitation phase. Vast majority of the remaining spots were either common to all the three phases or belonged to replicating phase proteins. 
non-culturable phase were compared to log phase culture of $M$. tuberculosis H37Rv by two dimensional gel electrophoresis (2-DE). Representative commassie blue stained 2-DE gels were generated by the software from triplicate gels of three independent samples for each condition i.e. replicating (Figure 1A), non-culturable (Figure 1B) and resuscitation phase (Figure 1C) and differentially expressed protein spots were analysed using the software program PDQuest. The differential expression of protein spots found in non-culturable phase were 107 and in resuscitation phase were 112 compared to $\log$ phase culture of M. tuberculosis H37Rv. Student t-test was used for the statistical analysis by PDQuest software. The system picked up the spots with differential intensity of significant levels inbuilt in the system. Matching was further improved by manually checking and confirming the potential spots of interest. After excluding the streaks and manually confirming potential spots, 35 spots were found to be differentially expressed in non-culturable and resuscitation phase and only 14 protein spots were identified by MALDI-TOF mass spectrometry (Table 1). Out of 14 spots, six spots were more expressed in resuscitation and eight spots were in non-culturable phase. The identity of protein spots with accession no., mascot score, sequence coverage and predicted functions is given in table 1.

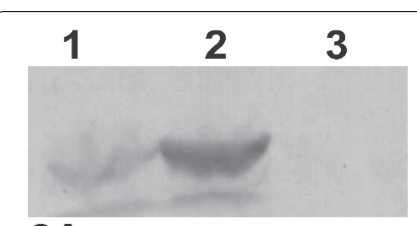

2A

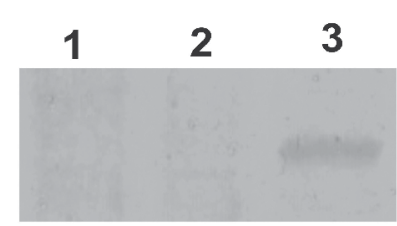

2C

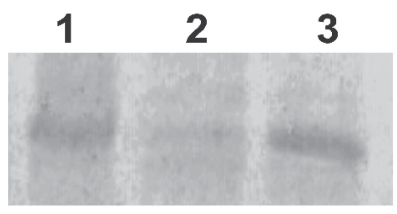

2E

Figure 2: Differential expression of the five identified proteins i.e. Rv2031c (2A), Rv3418c (2B), Rv1308 (2C), Rv2623 (2D) and Rv1479 (2E) in replicating (Lane 1 ), non-culturable (Lane 2 ) and resuscitation phase (Lane 3 ) were confirmed by western immunoblotting by using either monoclonal antibody obtained from Colorado state university or polyclonal antibody raised in rabbit.

\section{Validation of identified proteins by western blotting}

Western blot analysis was carried out to confirm differential expression of some of the identified proteins in replicating (Figure 2, lane 1), non-culturable (Figure 2, lane 2) and resuscitation phase (Figure 2, lane 3). Five of the fourteen proteins identified in the study were confirmed by western blotting. The experiment included three proteins, Rv2031c (Figure 2A), Rv3418c (Figure 2B) and Rv2623 from nonculturable cells (Figure 2D) and two proteins, Rv1308 (Figure 2C) and Rv1479 (Figure 2E) from resuscitation phase, identified by 2 -DE gel analysis for confirmation by western blotting. Western blot analysis results were found similar to the findings of 2-DE analysis.

\section{Transcriptional profiling of all the identified proteins by qRT-PCR}

The 14 differentially expressed proteins identified in 2-DE were further analysed by real time-PCR to determine the transcriptional profile at mRNA level (Figure 3). The average relative expression ratios of all the fourteen genes were observed in the resuscitation and non-culturable phase compared to replicating phase RNA of $M$. tuberculosis H37Rv. 16S rRNA was used for normalization of cDNA and specific internal primers were designed for each gene given in table 2. Average relative expression ratio of all the genes have been given in table 3 . The differential expression profile for all the fourteen genes was comparable to that of $2-\mathrm{DE}$, except the relative expression ratio varied. Results suggest that the proteins differentially expressed at translational level are also differentially expressed at transcriptional level. The only exception was Rv2667, in which case, the relation was inversed at mRNA level showing over expression in nonculturable phase (Figure 3, Table 3).

\section{Scanning electron microscopy revealed the morphological alteration during transition of growth phases}

The morphological changes of the replicating, non-culturable and resuscitation phase bacilli of $M$. tuberculosis $\mathrm{H} 37 \mathrm{Rv}$ was analyzed by SEM (Figure 4). The cells in the log phase were rod shaped having smooth surface measuring 2.98-3.82 $\mu \mathrm{m}$ in length. Most of the cells existed in isolated forms. The non-culturable (NC) cells formed distinct spherical/ovoid aggregates (ranging from 10 to $24 \mu \mathrm{m}$ in diameter) consisting of tightly packed cells. Cell size ranged from 1.04 to $1.63 \mu \mathrm{m}$. almost all the NC cells existed as aggregates. In contrast, free bacilli were observed among aggregates in the resuscitation phase after 7 days as evident in low magnification micrographs. Spore-like features were also noticed in the NC phase. The individual cells were morphologically similar in NC and resuscitation phase except that the length of the resuscitated cells was more than NC bacilli, measuring in the range of 1.49 to $2.23 \mu \mathrm{m}$. Moreover, the resuscitation phase sample had more subpopulation of elongated cells than ovoid population in NC phase. M. tuberculosis cells during the period of non-culturability

Table 1: Identity of 2-DE protein spots unique to non-culturable and resuscitation phase of $M$. tuberculosis H37Rv.

\begin{tabular}{|c|c|c|c|c|c|c|c|}
\hline S.no./ Spot no & Protein identification & $\begin{array}{l}\text { Accession } \\
\text { no }\end{array}$ & $\begin{array}{l}M_{\mathrm{r}} \\
\text { theoretical }\end{array}$ & $\begin{array}{l}\text { pl } \\
\text { theoretical }\end{array}$ & $\begin{array}{l}\text { MASCOT } \\
\text { score }^{a}\end{array}$ & $\begin{array}{l}\text { Sequence } \\
\text { coverage (\%) }\end{array}$ & Gene product ${ }^{b}$ \\
\hline 1/ SSP0004 & Resuscitation phase & Rv0009 & 19.28 & 6.2 & 61 & 41 & Peptidyl cis-trans isomeraseA \\
\hline 2/ SSP0007 & Non-culturable phase & Rv0046c & 40.09 & 4.8 & 66 & 35 & Inositol 1-phosphate synthetase \\
\hline 3/ SSP3104 & Non-culturable phase & Rv3417c & 56.69 & 4.85 & 180 & 59 & $60 \mathrm{KDa}$ chaperonin 1 (groEL1) \\
\hline 4/ SSP1001 & Nonculturable phase & Rv2031c & 16.21 & 4.75 & 65 & 43 & HspX (heat shock protein) \\
\hline 5/ SSP2303 & Resuscitation phase & Rv2667 & 26.62 & 5.5 & 52 & 28 & Probable ATP dependent protease (c/pC2) \\
\hline 6/ SSP3003 & Non-culturable phase & Rv3418c & 10.77 & 4.3 & 107 & 61 & $10 \mathrm{KDa}$ chaperonin (groES) \\
\hline 7/ SSP3204 & Non-culturable phase & Rv2744c & 29.25 & 5.7 & 53 & 34 & $35 \mathrm{KDa}$ alanine rich protein \\
\hline 8/ SSP4103 & Non-culturable phase & Rv3786c & 44.94 & 5.04 & 64 & 24 & Hypothetical protein \\
\hline 9/ SSP5102 & Resuscitation phase & Rv0685 & 43.56 & 5.11 & 79 & 36 & Iron-regulated elongation factor (EF-TU) \\
\hline 10/ SSP5706 & Resuscitation phase & Rv1308 & 59.28 & 4.78 & 50 & 46 & Probable ATP synthase a-chain \\
\hline 11/ SSP6505 & Non-culturable phase & Rv2623 & 31.65 & 5.55 & 127 & 40 & Conserved hypothetical \\
\hline 12/ SSP7102 & Resuscitation phase & Rv1479 & 40.76 & 6.35 & 108 & 27 & Transcriptional regulatory protein MoxR1 \\
\hline 13/ SSP7504 & Non-culturable phase & Rv2626c & 15.51 & 4.77 & 68 & 35 & Conserved hypothetical \\
\hline 14/ SSP7609 & Resuscitation phase & Rv3015c & 34.21 & 4.48 & 50 & 15 & Conserved hypothetical \\
\hline
\end{tabular}

a) MASCOT protein scores greater than 48 for mycobacterial proteins are considered significant $(p<0.05)$.

b) Refers to the M. tuberculosis H37Rv gene classification of the Sanger Institute. 


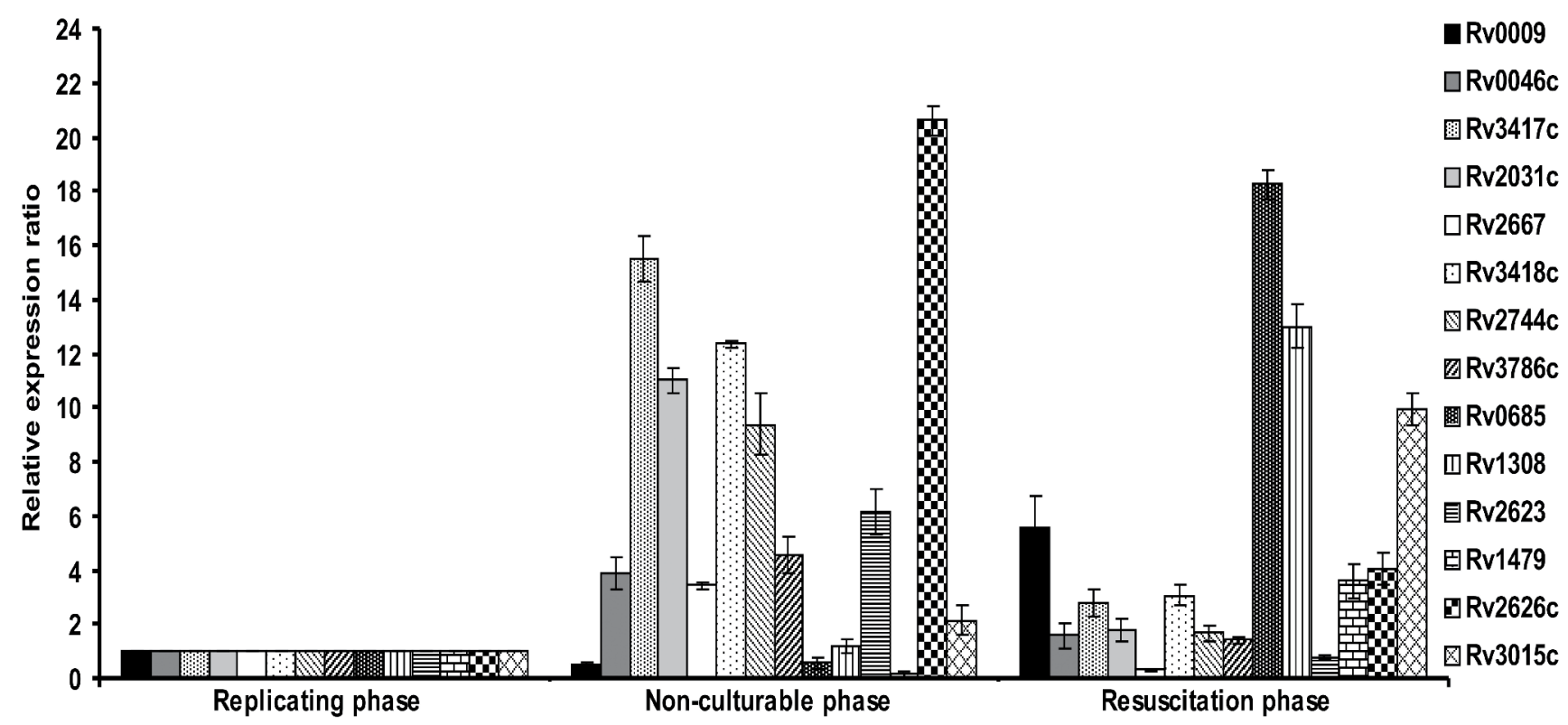

Figure 3: Relative expression analysis of all the 14 genes identified in 2-DE experiments was examined in replicating, non-culturable and resuscitation phase of M. tuberculosis H37Rv by real time-PCR. RNA was isolated from the triplicate samples used for 2-DE experiments. Replicating phase RNA was used as a positive calibrator and $16 \mathrm{~s}$ rRNA was used as a reference gene for normalization. Data represents the average relative expression ratio found significant at $p<0.05$ of the triplicate independent samples with standard deviation.

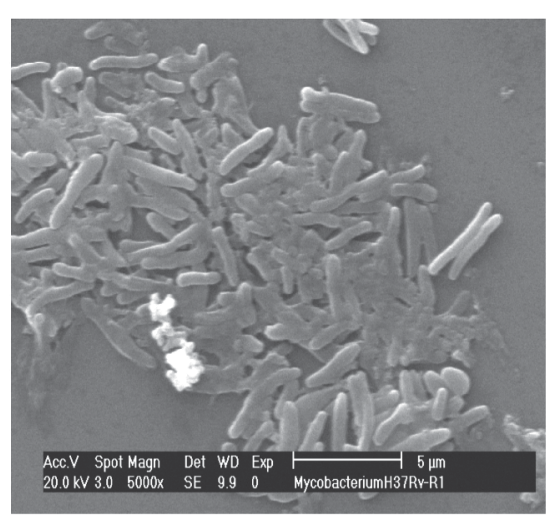

4A

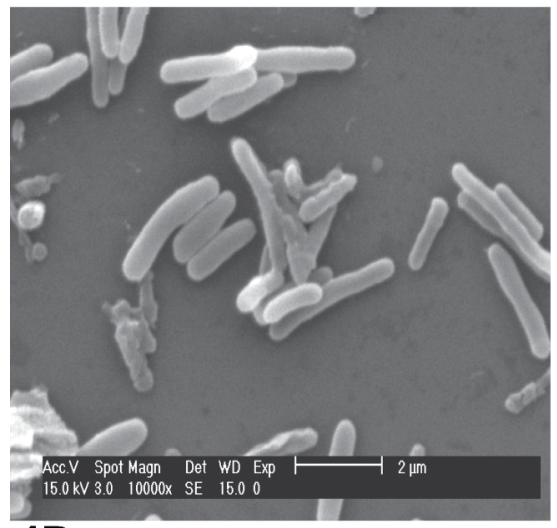

4D

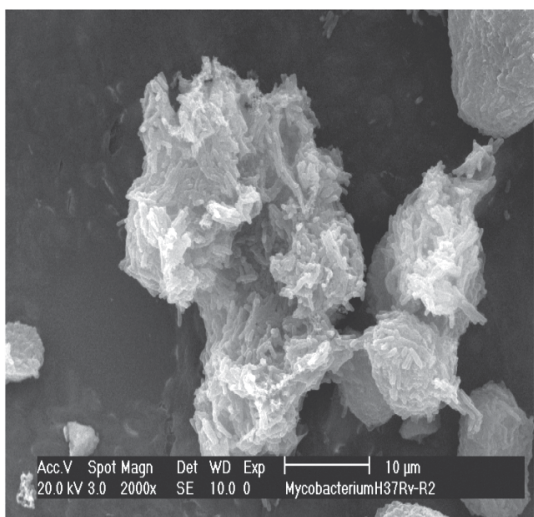

4B

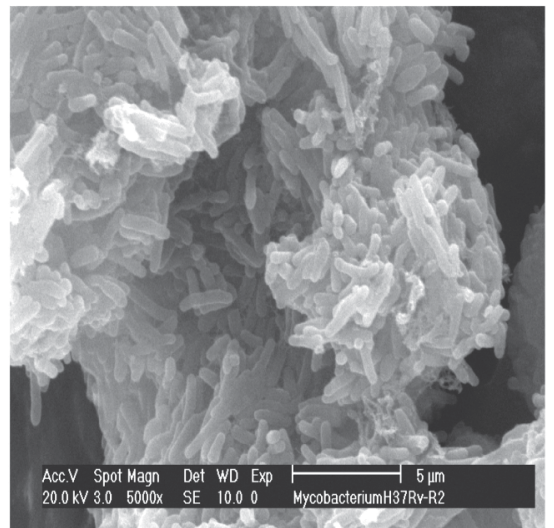

4E

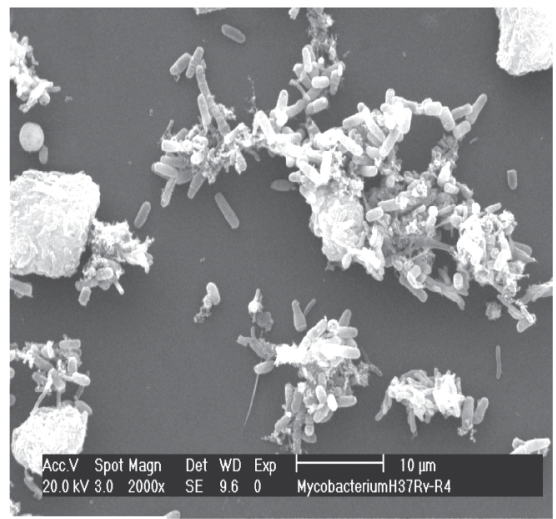

4C

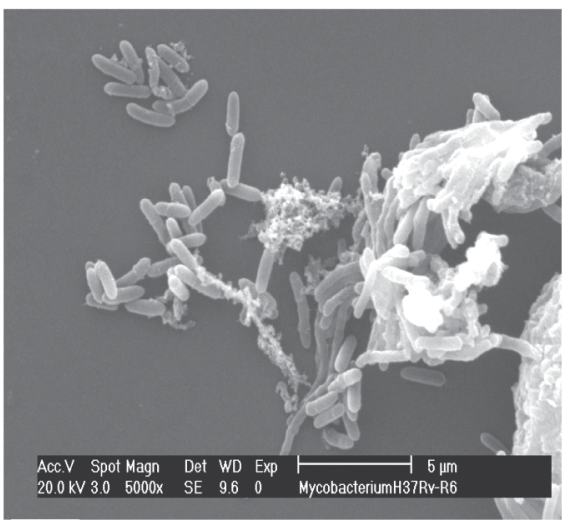

4F

Figure 4: Scanning electron microscopy of $M$. tuberculosis $\mathrm{H} 37 \mathrm{Rv}$ bacilli was examined in replicating (4A,4D), non-culturable (4B,4E) and resuscitation phase $(4 \mathrm{C}, 4 \mathrm{~F})$ at $2000 \mathrm{x}$ to $10000 x$ magnification in a Philips XL30 ESEM. Each sample was analysed from at least 20 different fields from two stubs to assess the morphological changes occurring during the progression of culture from replicating to non-culturable to resuscitation phase.

have been reported to be coccoid or ovoid forms which contrasted with the characteristic elongated curved rod shape of exponentially growing cells. The laser diffraction studies suggest that the cell size after one week of resuscitation composed of size 2, 4-6, and 10 $\mu \mathrm{m}$ [7].

M. tuberculosis uses latency as a tool to survive for indefinite period of time in the host tissues. The dormant bacilli in latent stage are resistant to standard anti-TB drugs effective against replicating bacteria and go in the long-term reservoir for the future progression of disease and contagion. These dormant bacilli can reactivate in favorable conditions and cause active disease with clinical symptoms. Hence, understanding the entry and exit of $M$. tuberculosis to and 
Table 2: Internal primers used for real time-PCR study of the identified genes in 2-DE analysis of $M$. tuberculosis H37Rv.

\begin{tabular}{|c|c|c|}
\hline S. no. & Genes & Primers (5' - 3') \\
\hline \multirow[t]{2}{*}{1} & \multirow[t]{2}{*}{ Rv0009 } & $\mathrm{F}=\mathrm{CGCAGGGCACCAAGGACTAT}$ \\
\hline & & R=GAATTGCAGCTCGGGGTGGAACT \\
\hline 2 & Rv0046c & $\begin{array}{l}\mathrm{F}=T G A A C G G C T G G A G T C C A A G A A G A T \\
R=T G T A C T C C A G G T T C A A C G G C A C A T\end{array}$ \\
\hline 3 & Rv3417c & $\begin{array}{l}\mathrm{F}=\mathrm{TCCTGCTGCACCAAGACAAGATCA} \\
\mathrm{R}=\mathrm{CTTTCAACGTCTTGCGAATCGCGT}\end{array}$ \\
\hline 4 & Rv2031c & $\begin{array}{l}\mathrm{F}=\text { =AATTCGCGTACGGTTCCTTCGTTC } \\
\mathrm{R}=\text { AGTTGGTGGACCGGATCTGAATGT }\end{array}$ \\
\hline 5 & Rv2667 & $\begin{array}{l}\mathrm{F}=\text { CGAAGCCACCACACTGGATTCAAA } \\
\mathrm{R}=\mathrm{TGAGCACTCCCAACAACAGGTGAT}\end{array}$ \\
\hline 6 & Rv3418c & $\begin{array}{l}\mathrm{F}=\text { TGAACATCAAGCCACTCGAGGACA } \\
\mathrm{R}=\text { CTTCTCCTTGGCGGTGTCAGGAAT }\end{array}$ \\
\hline 7 & Rv2744c & $\begin{array}{l}\mathrm{F}=\text { =ACGCTGCCAAGGCCACCGAATACA } \\
\mathrm{R}=\text { CAACGATGCGCTGACCTGCTCCTG }\end{array}$ \\
\hline 8 & Rv3786c & $\begin{array}{l}\mathrm{F}=\text { ACCGATCTTTGTTGTTTGGCTACG } \\
\mathrm{R}=\mathrm{GAAGTCGACACCGGGATGGAAACC}\end{array}$ \\
\hline 9 & Rv0685 & $\begin{array}{l}\mathrm{F}=\text { GTGACGCGAAGTGGGTTGCCTCTG } \\
\mathrm{R}=\mathrm{GATCACGCCGCGCTCCACACG}\end{array}$ \\
\hline 10 & Rv1308 & $\begin{array}{l}\mathrm{F}=\text { CGAGACCAAGGCCAACGACATC } \\
\mathrm{R}=\text { CTTCCGGCGACCTCTTTCATAGC }\end{array}$ \\
\hline 11 & Rv2623 & $\begin{array}{l}\mathrm{F}=\mathrm{GGCAGCCGTTCCCACATT} \\
\mathrm{R}=\mathrm{CGAGCCGTCAACGCCAACTA}\end{array}$ \\
\hline 12 & Rv1479 & $\begin{array}{l}\mathrm{F}=\mathrm{GATGCTCGTCGGCCTGCTGTCCA} \\
\mathrm{R}=\text { CCTCCCTGCCTTGCCGGTAGATGC }\end{array}$ \\
\hline 13 & Rv2626c & $\begin{array}{l}\mathrm{F}=\text { CGATCTGCGGGGACGACGAC } \\
\mathrm{R}=\text { CGGAACACGGCGGACCTGAT }\end{array}$ \\
\hline 14 & Rv3015c & $\begin{array}{l}\mathrm{F}=\text { AGCGCAGCAGAATTAGTGCGGTAT } \\
\mathrm{R}=\text { ACAAATGCCGCGACAGCATCCAAAT }\end{array}$ \\
\hline
\end{tabular}

from dormancy is crucial for effective treatment of tuberculosis. Several studies have been performed to study the in vitro entry of tubercle bacilli into dormancy, which appears to mimic latent infection [22-25] but very little is known about the way by which bacilli gets exit from dormancy.

Prolonged incubation of $M$. tuberculosis culture in vitro in extended stationary phase for 5-6 months produces non-culturable cells, which have characteristic features of no cell division and thickened cell wall $[6,10]$. These NC cells can be resuscitated by incubation in growth medium having resuscitation promoting factors $[6,7]$. Resuscitation promoting factors (Rpfs) are known to involve in the cleavage of peptidoglycan and loosening of cell wall during resuscitation so that cells become communicable with the extra cellular stimuli [16]. Comparative protein analysis of replicating. Nonculturable and resuscitation phases by 2-DE gel electrophoresis led to identification of six proteins exclusively expressed in resuscitation phase and eight proteins in NC state of M. tuberculosis H37Rv.

The proteins identified in non-culturable state belonged to virulence, detoxification and adaptation pathway (Rv2031c hspX, $\mathrm{Rv} 3417 \mathrm{c}, 60 \mathrm{kDa}$ chaperone (groEL1); Rv3418c, groES;), intermediate metabolism and respiration (Rv0046), conserved hypothetical (Rv2744c, $35 \mathrm{KDa}$ alanine rich protein; Rv2623, Rv2626c and $\mathrm{Rv} 3786 \mathrm{c})$. All eight proteins identified by 2-DE analysis were found to be related to stress and dormancy. HspX (Rv2031c) is a stress protein specifically up regulated by $M$. tuberculosis during stationary growth or in vitro conditions mimicking relevant aspects of latency and functions in maintenance of long-term viability during latent, asymptomatic infection [26]. Rv3418, chaperone 10 (GorES, $10 \mathrm{kDa}$ ) has been shown to be an important T-cell antigen in tuberculosis patients and acts in concert with chaperone 60 (GroEL; Rv3417). These proteins prevent the misfolding of the protein, catalyze protein folding and proper assembly of unfolded polypeptides generated under stress conditions and shows increased expression inside macrophage [24,27]. Rv2744c (35 kDa chaperon) is a conserved alanine rich protein and is upregulated at high temperatures [22]. Both Rv2623 and Rv2626 are among the most highly induced genes when the tubercle bacillus is subjected to hypoxia and nitrosative stress conditions. M. tuberculosis Rv2623 appears to regulate mycobacterial growth in vitro and in vivo, its induction occurs when $M$. tuberculosis
Table 3: Relative expression of all the genes of $M$. tuberculosis H37Rv during non-culturable and resuscitation phase by real time-PCR using 16S rRNA as a reference gene for normalization and log phase RNA as a positive calibrator.

\begin{tabular}{|l|l|l|}
\hline \multirow{2}{*}{ Genes } & \multicolumn{2}{|c|}{ Average relative expression ratio ( \pm SD) } \\
\cline { 2 - 3 } & Non-culturable phase & Resuscitation phase \\
\hline Rv0009 & $0.483666667(0.087030646)$ & $5.518966667(1.206185762)$ \\
\hline Rv0046c & $3.8716333330(.586605833)$ & $1.5628(0.493261351)$ \\
\hline Rv3417c & $15.50133333(0.841344955)$ & $2.7593(0.496496314)$ \\
\hline Rv2031c & $10.99387(0.431599)$ & $1.739333(0.409087)$ \\
\hline Rv2667 & $3.418(0.149292)$ & $0.305333(0.073276)$ \\
\hline Rv3418c & $12.3394(0.108887)$ & $3.044333(0.378995)$ \\
\hline Rv2744c & $9.376667(1.656)$ & $1.107707(0.281048)$ \\
\hline Rv3786c & $4.560367(0.660619)$ & $1.394767(0.101188)$ \\
\hline Rv0685 & $0.554(0.219335)$ & $18.238(0.553057)$ \\
\hline Rv1308 & $1.151667(0.24893)$ & $13.00333(0.772032)$ \\
\hline Rv2623 & $6.146(0.7485)$ & $0.82622(0.074581)$ \\
\hline Rv1479 & $0.198467(0.038885)$ & $3.5959(0.619312)$ \\
\hline Rv2626c & $20.6032(0.524988)$ & $4.025767(0.586161)$ \\
\hline Rv3015c & $2.1459(0.507916)$ & $9.933067(0.596481)$ \\
\hline & & \\
\hline
\end{tabular}

encounters conditions associated with growth arrest, such as the intracellular milieu of macrophages and in the lungs of mice with chronic tuberculosis $[23,24,28]$. Rv2626 is a conserved hypothetical protein and induced under aerobic and low oxygen conditions [23]. Significantly increased expression of $h s p \mathrm{X}$ (Rv2031c), Rv2623c, and Rv2626 was shown by real time-PCR after the onset of Th1-mediated immunity in the mouse model of tuberculosis [12,14,29]. Rv0046 (Myo-inositol-1-Phosphate Synthase) encodes inositol-1-phosphate synthase, the $\mathrm{NAD}^{+}$dependent enzyme that isomerizes glucose-6phosphate to myo-inositol-1-phosphate, the first committed step in the production of all inositol-containing compounds, including phospholipids [30]. L-myo-inositol is vital for the biogenesis of mycothiol, phosphatidyl inositol and glycosyl phosphatidyl inositol which anchors linked to complex carbohydrates in M. tuberculosis. All these cellular components are thought to play important roles in host-pathogen interactions and in the survival of the pathogen within the host. The enzyme exists in a cytoplasmic form in a wide range of plants, animals and fungi [31].

The proteins expressed in resuscitation phase belonged to regulatory protein $(\mathrm{Rv} 1479, \operatorname{mox} R)$, intermediate metabolism and respiration (Rv2667, clpC2; Rv1308, atpA), Information pathway (Rv0685, tuf; Rv0009, probable iron-regulated peptidyl-prolyl cistrans isomerase (ppiA) and Conserved hypothetical (Rv3015c) functional category. Resuscitation represents resumption of growth after exit from dormancy. Rv1308 codes for an ATP-synthase, which is involved in generation of ATP from ADP in the presence of a proton gradient across the membrane [23]. Rv2667 has been annotated as a possible ATP-dependent protease. ATP-binding subunit clpC2 possibly hydrolyzes peptides or proteins in presence of ATP (http://www.tbgenomics.org). MoxR1 (Rv1479) is reported to be a putative regulatory protein involved in the transcription hence could be important in the active transcription of resuscitated cells [32]. Both petidyl cis-trans isomerase (Rv0009) and elongation factor EF-Tu (Rv0685) have a role in protein biosynthesis. Rv0009 is an iron-regulated isomerase and accelerates the folding of proteins while elongation factor EF-Tu (Rv0685) is annotated as an iron-regulated elongation factor that promotes the GTP-dependent binding of aminoacyl-t-RNA to the A-site of ribosomes during protein biosynthesis. The proteins upregulated during resuscitation were found to be down regulated during nutrient starvation $[23,25,32,33]$. During transition from non-culturable state to resuscitation phase, bacteria has to efflux the pool of energy and undergo transcriptional activation of majority of the genes involved in the metabolic energy generation and cell wall modification, which became quiescent during dormancy hence these genes may also be used as a marker for the resuscitation.

All the fourteen $M$. tuberculosis proteins identified by $2-\mathrm{D}$ electrophoresis during two phases of growth were also regulated at mRNA level as revealed by qRT-PCR analysis. Using replicating phase 
RNA as a positive calibrator, $16 \mathrm{~S}$ rRNA was used for normalization of cDNA. All 14 genes which were identified in 2-DE analysis as differentially expressed proteins in non-culturable and resuscitation phase showed differential expression at transcriptional level also except that the relative expression ratio varied. . The only exception was Rv2667, in which case the relation was inversed at mRNA level showing over expression in nonculturable phase compared to resuscitation phase (Figure 3, Table S2). The similar transcriptional up regulation of Rv2667 gene has been earlier reported in the noncultural state in the stationary phase in comparison to the expression in logarithmic phase and during chronic infection in mice [34,35]. The transcription data can suggest the presence of protein but not the level to expect to see the protein. However the essentiality and role of Rv2667 in life cycle of $M$. tuberculosis remains to be proven. The expression of few proteins, viz. Rv2031c, Rv2623 and Rv3418c (nonculturable state) and Rv1308 and Rv1479 (resuscitation phase) was also validated by western blotting. The study clearly demonstrates that the proteins identified in this study are regulated at transcriptional and translational levels and could be further evaluated at molecular level by knocking off the genes. The study does not represent the total proteome of M. tuberculosis in NC and resuscitation phase. However, the unique proteins identified could be examined for their role in resuscitation from dormant stage. Proteins identified in resuscitation phase suggest that the physiological and metabolic energy generation is required to facilitate the resuscitation of $\mathrm{NC}$ bacilli and the identified proteins in resuscitation phase are likely to contribute to the exit of dormant bacilli into active growth phase and could become potential drug targets.

\section{Acknowledgements}

We thank the Director of CDRI and JALMA for facilities and support. Financial support from CSIR (NIF) and DBT is acknowledged. RKG was supported by SRF of CSIR. This is the CDRI communication number $82 / 2011 / R S$.

\section{References}

1. Global tuberculosis control: epidemiology, strategy, financing. WHO report 2009 (WHO/HTM/TB/2009.411)

2. Wayne Lg (1960) The bacteriology of respected tuberculous pulmonary lesions. 2. Observations on bacilli which are stainable but which cannot be cultured. Am Rev Respir Dis 82: 370-377.

3. Russell-Goldman E, Xu J, Wang X, Chan J, Tufariello JM (2008) A Mycobacterium tuberculosis Rpf double-knockout strain exhibits profound defects in reactivation from chronic tuberculosis and innate immunity phenotypes. Infect Immun 76: 4269-4281.

4. Wayne LG, Hayes LG. (1996) An in vitro model for sequential study of shiftdown of Mycobacterium tuberculosis through two stages of nonreplicating persistence. Infect Immun 64: 2062-2069.

5. Boon C, Li R, Qi R, Dick T (2001) Proteins of Mycobacterium bovis BCG induced in the Wayne dormancy model. J Bacteriol 183: 2672-2676.

6. Shleeva MO, Mukamolova GV, Telkov MV, Berezinskaia TL, Syroeshkin AV, et al. (2003) [Formation of nonculturable Mycobacterium tuberculosis and their regeneration]. Mikrobiologiia 72: 76-83.

7. Shleeva MO, Bagramyan K, Telkov MV, Mukamolova GV, Young M, et al (2002) Formation and resuscitation of 'non-culturable' cells of Rhodococcus rhodochrous and Mycobacterium tuberculosis in prolonged stationary phase. Microbiology 148: 1581-1591.

8. Tufariello JM, Jacobs WR Jr, Chan J (2004) Individual Mycobacterium tuberculosis resuscitation-promoting factor homologues are dispensable for growth in vitro and in vivo. Infect Immun 72: 515-526.

9. Tufariello JM, Mi K, Xu J, Manabe YC, Kesavan AK et al. (2006) Deletion of the Mycobacterium tuberculosis resuscitation-promoting factor Rv1009 gene results in delayed reactivation from chronic tuberculosis. Infect Immun 74: 2985-2995.

10. Biketov S, Potapov V, Ganina E, Downing K, Kana BD, et al. (2007) The role of resuscitation promoting factors in pathogenesis and reactivation of Mycobacterium tuberculosis during intra-peritoneal infection in mice. BMC Infect Dis 7: 146

11. Mukamolova GV, Turapov O, Malkin J, Woltmann G, Barer MR (2010) Resuscitation-promoting factors reveal an occult population of tubercle Bacilli in Sputum. Am J Respir Crit Care Med 181: 174-180.

12. Schaeffer ML, Agnihotri G, Volker C, Kallender H, Brennan PJ, et al. (2001) Purification and biochemical characterization of the Mycobacterium tuberculosis beta-ketoacyl-acyl carrier protein synthases KasA and KasB. J
Biol Chem 276: 47029-47037.

13. Betts JC, Lukey PT, Robb LC, McAdam RA, Duncan K (2002) Evaluation of a nutrient starvation model of Mycobacterium tuberculosis persistence by gene and protein expression profiling. Mol Microbiol 43: 717-731.

14. Rosenkrands I, King A, Weldingh K, Moniatte M, Moertz E, et al. (2000) Towards the proteome of Mycobacterium tuberculosis. Electrophoresis 21: 3740-3756

15. Gupta RK, Srivastava BS, Srivastava R (2010) Comparative expression analysis of rpf-Like genes of Mycobacterium tuberculosis H37Rv under different physiological stress and growth conditions. Microbiology 156: 27142722.

16. Salina EG, Vostroknutova GN, Shleeva MO, Kaprel'iants AS (2006) [Cellcell interactions during formation and reactivation of "nonculturable" mycobacteria]. Mikrobiologiia 75: 502-508.

17. Brodie AF, Kalra VK, Lee SH, Cohen NS (1979) Properties of energytransducing systems in different types of membrane preparations from Mycobacterium phlei--preparation, resolution, and reconstitution. Methods Enzymol 55: 175-200.

18. Bisht D, Singhal N, Sharma P, Venkatesan K (2007) An improved sample preparation method for analyzing mycobacterial proteins in two-dimensional gels. Biochemistry (Mosc) 72: 672-674.

19. Görg A, Obermaier C, Boguth G, Harder A, Scheibe B, et al. (2000) The current state of two-dimensional electrophoresis with immobilized $\mathrm{pH}$ gradients. Electrophoresis 21: 1037-1053.

20. Harlow E, Lane D (1988) Antibodies: A Laboratory Manual. Cold Spring Harbor, NY, Cold Spring Harbor Laboratory Press 196-238.

21. Pfaffl MW (2001) A new mathematical model for relative quantification in realtime RT-PCR. Nucleic Acids Res 29: e45.

22. Stewart GR, Wernisch L, Stabler R, Mangan JA, Hinds J, et al. (2002) Dissection of the heat-shock response in Mycobacterium tuberculosis using mutants and microarrays. Microbiology 148: 3129-3138.

23. Rosenkrands I, Slayden RA, Crawford J, Aagaard C, Barry CE 3rd, et al (2002) Hypoxic response of Mycobacterium tuberculosis studied by metabolic labeling and proteome analysis of cellular and extracellular proteins. J Bacteriol 184: 3485-3491.

24. Sherman DR, Voskuil M, Schnappinger D, Liao R, Harrell MI, et al. (2001) Regulation of the Mycobacterium tuberculosis hypoxic response gene encoding alpha -crystallin. Proc Natl Acad Sci U S A 98: 7534-7539.

25. Betts JC, Lukey PT, Robb LC, McAdam RA, Duncan K (2002) Evaluation of a nutrient starvation model of Mycobacterium tuberculosis persistence by gene and protein expression profiling. Mol Microbiol 43: 717-731.

26. Desjardin LE, Hayes LG, Sohaskey CD, Wayne LG, Eisenach KD (2001) Microaerophilic induction of the alpha-crystallin chaperone protein homologue (hspX) mRNA of Mycobacterium tuberculosis. J Bacteriol 183: 5311-5316.

27. He H, Hovey R, Kane J, Singh V, Zahrt TC (2006) MprAB is a stressresponsive two-component system that directly regulates expression of sigma factors SigB and SigE in Mycobacterium tuberculosis. J Bacteriol 188: 2134-2143.

28. Drumm JE, Mi K, Bilder P, Sun M, Lim J, et al. (2009) Mycobacterium tuberculosis universal stress protein Rv2623 regulates bacillary growth by ATP-Binding: requirement for establishing chronic persistent infection. PLoS Pathog 5: e1000460.

29. Shi L, Jung YJ, Tyagi S, Gennaro ML, North RJ (2003) Expression of Th1mediated immunity in mouse lungs induces a Mycobacterium tuberculosis transcription pattern characteristic of nonreplicating persistence. Proc Natl Acad Sci USA 100: 241-246.

30. Bachhawat N, Mande SC (1999) Identification of the INO1 gene of Mycobacterium tuberculosis H37Rv reveals a novel class of inositol-1phosphate synthase enzyme. J Mol Biol 291: 531-536.

31. Majumder AL, Chatterjee A, Ghosh Dastidar K, Majee M (2003) Diversification and evolution of L-myo-inositol 1-phosphate synthase. FEBS Lett 553: 3-10.

32. Jungblut PR, Schaible UE, Mollenkopf HJ, Zimny-Arndt U, Raupach B, et al. (1999) Comparative proteome analysis of Mycobacterium tuberculosis and Mycobacterium bovis BCG strains: towards functional genomics of microbial pathogens. Mol Microbiol 33: 1103-1117.

33. Walters SB, Dubnau E, Kolesnikova I, Laval F, Daffe M, et al. (2006) The Mycobacterium tuberculosis PhoPR two-component system regulates genes essential for virulence and complex lipid biosynthesis. Mol Microbiol 60: 312-330.

34. Salina EG, Mollenkopf HJ, Kaufmann SH, Kaprelyants AS (2009) M tuberculosis Gene Expression during Transition to the "Non-Culturable" State. Acta Naturae 1: 73-77.

35. Bacon J, Alderwick LJ, Allnutt JA, Gabasova E, Watson R1, et al. (2014) Nonreplicating Mycobacterium tuberculosis elicits a reduced infectivity profile with corresponding modifications to the cell wall and extracellular matrix. PLoS One 9: e87329. 